\title{
The Chemical Origin of Defects on Silicon Dioxide Exposed to Ethanol
}

\author{
Che-Chen Chang* and Ming-Chi Shu \\ Department of Chemistry, National Taiwan University, Taipei, Taiwan, R.O.C. 10617
}

Received: November 1, 2002; In Final Form: February 25, 2003

\begin{abstract}
The adsorption and reaction of ethanol on the metal-free, pure silicon dioxide surface have been studied as a model system to explore the chemical origin of the defects which are detrimental in the gate oxide exposed to chemical vapors. In addition to molecular adsorption, ethanol decomposed to the extent that a variety of species including ethyl, ethoxy, and hydroxyl were produced even at the surface temperature of $115 \mathrm{~K}$. The silicon dioxide surface was selective for the formation of acetaldehyde through cleavage of the $\mathrm{C}-\mathrm{H}$ bond. The bare surface, however, was more selective for ethanol conversion to ethylene than the surface covered by fragments and products. Comparison of static secondary ion mass spectra taken from the surface exposed to deuterated and nondeuterated ethanol, respectively, showed that the $\mathrm{C}-\mathrm{H}, \mathrm{Et}-\mathrm{OH}$, and $\mathrm{EtO}-\mathrm{H}$ bonds were disrupted during the surface decomposition of ethanol. Hydroxyl hydrogen of ethanol readily exchanged with silanol hydrogen of the surface. The formation of $\mathrm{Si}-\mathrm{H}$ and $\mathrm{SiO}-\mathrm{H}$ bonds suggests that hydrogen concentration will increase on the metal-free silicon dioxide surface exposed to organic vapors. Its implication to the generations of defects in the silicon dioxide framework and of the stress-induced leakage current will be discussed.
\end{abstract}

\section{Introduction}

Silicon dioxide, the native oxide of silicon, is the dielectric of choice in present-day electronics devices. It constitutes the insulating layer of the metal oxide semiconductor (MOS) field effect transistors found in the integrated circuit. ${ }^{1}$ The silicon dioxide layer, as the narrowest feature on chips, is believed to be one of the key limiting factors for fabricating increasingly smaller silicon-based transistors. ${ }^{2,3}$ It has been shown that a fouratom layer is the fundamental physical limit for silicon dioxide based insulators. ${ }^{4}$ With the past success in surmounting all the challenges from the limitations for the progress of microelectronics, such as those related to architecture, process technology, and material, ${ }^{5}$ scaling of CMOS down beyond the target values ${ }^{6}$ of $35 \mathrm{~nm}$ after the year of 2014 is thought to be feasible ${ }^{7}$ using very thin silicon substrates on insulator and with two gates for the control of the charge carriers.

As indicated in the latest International Technology Roadmap for Semiconductors (ITRS), bulk CMOS may run into performance constraints at $70 \mathrm{~nm}$, below which thin films of silicon on insulator and fully depleted channels will have to be resorted to. ${ }^{5}$ The properties of the silicon dioxide layer in these films and of its interface with silicon will then critically affect the performance of the new-generation MOS transistors before an alternative gate dielectric, such as zirconium oxide ${ }^{8}$ and hafnium oxide, ${ }^{9}$ are employed. They will determine if the thickness of the oxide layer in silicon MOS transistors can ever approach its fundamental physical limit.

A complete understanding about the chemical properties of the silicon dioxide thin layer in the vicinity of the interface is thus imperative. It is suggested that a forerunner and possible cause of ultimate dielectric breakdown is the charge trapping and buildup on defect sites in the silicon dioxide layer. ${ }^{10-12}$ The buildup results in a tunneling current, the stress-induced leakage current, flowing through the oxide which becomes greater during device operation. These defect sites are either

* Address correspondence to this author. E-mail: cchang@ccms.ntu.edu.tw. present in the as-fabricated oxide ${ }^{13,14}$ or induced when carriers are injected from the contacts into the layer. ${ }^{13,15-18}$ Degradation of silicon dioxide films may thus primarily occur near the interfaces with contacting metals or semiconductors. ${ }^{10}$

In particular, degradation of the MOS structure has been attributed to the presence of dangling-bond defects ${ }^{19-21}$ in the interfaces to which hydrogen diffuses. ${ }^{10,19,22,23}$ Hydrogen is an impurity commonly found in silicon oxide films, with its concentration and distribution depending strongly on the growth condition. ${ }^{24}$ It may be released from its bonding site by hot electrons ${ }^{25,26}$ or holes ${ }^{18,27-28}$ when they cross the oxide. Defects containing ill-coordinated atoms as well as in the forms of $\equiv$ $\mathrm{Si}-\mathrm{H}$ and $\equiv \mathrm{Si}-\mathrm{OH}$ are generated near or in the gate electrode or the channel. ${ }^{10-12,16,22,23}$ Low-field leakage currents are also generated by exposure of the MOS structure to atomic hydrogen. ${ }^{23}$ In this case, a defect structure in the form of the neutral hydrogen bridge is produced in which the hydrogen atom replaces an oxygen atom and forms a complex with an oxygen vacancy. ${ }^{12}$ This atomic-hydrogen-induced defect has a higher concentration in the interface than the hydrogen-dangling bond defect. ${ }^{19,29,30}$ First-principles calculations also showed that the neutral hydrogen bridge is the trap mainly responsible for stressinduced leakage current through gate oxides. ${ }^{12}$

Hydrogen and other products generated from chemical reactions may also degrade the performance of silicon MOS integrated circuits. The increase in the number of charge traps observed in a humid atmosphere ${ }^{31}$ has already implied that hydrogen yielded from the reaction of water vapor with the silicon MOS structure may be part of the defect structure leading to device failure. Kinetics studies of the drain current generated from the combined action of ethanol vapor and drain voltage, in a without-gate n-channel MOS field effect transistor structure, showed that the magnitude of the current was determined by two processes of different time constants, both of which were a unique function of the reaction between ethanol molecules and the oxide. ${ }^{32}$ Under the action of ethanol, changes appeared in the structure, in which defects were introduced, at certain 
drain voltages. ${ }^{32}$ The defects became a source of electrically active centers. The numerical analysis ${ }^{17}$ of the measured low voltage static $\mathrm{I}-\mathrm{V}$ curve showed that these defects caused a significant increase in the total charge in the structure, with a positive net density high enough to cause an inversion channel. It was proposed, on the basis of the reversibility of the observed change in the drain current, that the charge induced in the structure was perhaps located mainly on the surface of the oxide, ${ }^{32}$ although the charge increase in the fixed states in the oxide provoked by the diffusion of ethanol molecules or the products of their surface reactions cannot be completely ruled out. ${ }^{10,12,16,32}$

Results of these studies reveal that the action of chemical vapors during fabrication of MOS structures as well as the chemical properties of the silicon dioxide interfaces may be vital to the ultimate downscaling of the silicon-based CMOS technology. At the fundamental physical limit for silicon dioxide based insulators of about four atoms across, two of them will be at the interfaces. ${ }^{4}$ The surface/interface will thus constitute a significant fraction of the dielectric layer. If the silicon MOS technology can evolve to this stage, the impacts of the surface/ interface characteristics to the MOS performance will be determinant.

This work was conducted in an attempt to contribute to the body of the knowledge in demand for the continuous downscaling of the silicon CMOS technology by exploring the microscopic origin of defects related to the hydrogen species generated on the metal-free, pure silicon dioxide surface from its reactions with chemical vapors. Ethanol was chosen as the model molecule for the reaction so as to capitalize on the existing knowledge ${ }^{32}$ and to provide some chemical insights on the buildup of defects on the silicon dioxide surface that may lead to the destructive breakdown of the gate oxide. The use of silicon dioxide samples of high purity is critical to this study. Even though silicon dioxide is generally considered for heterogeneous catalysis ${ }^{4,33,34}$ as one of the more innocuous supports, ${ }^{35}$ traces of metal impurities exhibit noticeable effects on the chemical properties of the sample. ${ }^{36,37}$ They act as reactive centers in the silicon dioxide network, displaying high reactivity toward catalytic reactions of organic compounds. ${ }^{38}$

The silicon dioxide films used in most of the studies reported in the literature were prepared by deposition from suspension in solutions, ${ }^{39,40}$ chemical vapor deposition, ${ }^{41,42}$ or by thermal oxidation of silicon. ${ }^{43,44}$ The films produced through deposition from suspension usually contain metal impurities. ${ }^{45}$ Chemical vapor deposition may incorporate oxidants into the silicon dioxide structure. ${ }^{41}$ The first study ${ }^{46}$ aimed to understand the reactions over pure silicon dioxide samples of hydrogencontaining compounds was conducted on a dried silica gel prepared by hydrolysis of ethyl orthosilicate in nitric acid, with impurity levels in the sample of 4 ppm in nickel and 4 ppm in sodium. No studies were reported about the details of hydrocarbon reactions on metal-free, high-purity silicon dioxide films prepared by thermal oxidation.

This paper presents results from experiments on ethanol reactions on the metal-free, high-purity silicon dioxide surface to elaborate upon the following questions: (1) Does ethanol decompose on the metal-free silicon dioxide surface? (2) If it does, to what extent do ethanol molecules decompose and what are the identities of their decomposition products? (3) How are some of these products formed during the ethanol reaction on silicon dioxide (i.e., which chemical bonds in ethanol are disrupted during the reaction and which new bonds are formed on the surface)? (4) What are the hydrogen-containing species produced from ethanol reactions on silicon dioxide? (5) Are $\mathrm{Si}-\mathrm{H}$ and $\mathrm{Si}-\mathrm{OH}$ surface species, which may be related closely to the charge buildup observed in the gate oxide, ${ }^{10-12,16}$ formed in the reaction and does their surface population increase with the ethanol exposure? Implications of the results obtained in this study will be discussed in the context of the role of surface reaction products on the stress-induced leakage current.

\section{Experimental Section}

Experiments were performed in a stainless steel ultrahigh vacuum system with a background pressure typically of $2 \times$ $10^{-10}$ Torr. The details of the system design are described elsewhere. ${ }^{47}$ Briefly, the system is pumped by a $500 \mathrm{~L} / \mathrm{s}$ turbomolecular pump and equipped for temperature-programmed desorption (TPD), static secondary ion mass spectrometry (SSIMS), Auger electron spectroscopy (AES), and low-energy electron diffraction (LEED).

The silicon dioxide samples employed in this work were prepared using n-type (Sb-doped, $\rho=0.0001-0.02 \Omega$-cm) Si(100) wafers acquired from International Wafer Service. After cleavage into approximately $12 \mathrm{~mm} \times 8 \mathrm{~mm} \times 0.5 \mathrm{~mm}$ rectangles, they were subjected to a wet-chemical cleaning process $^{59}$ to remove grease left on the sample. Silicon dioxide was then grown on the $\mathrm{Si}(100)$ surface by thermal oxidation in an oven at an elevated temperature of $\sim 1000 \mathrm{~K}$ in air for $6 \mathrm{~h}$. The thickness of the silicon dioxide layer formed was $\sim 100 \AA$, as revealed from the depth profiling of the sample surface using $\mathrm{X}$-ray photoelectron spectroscopy. After the growth, the sample was placed in a pocket of thin tantalum sheet, which provided the thermal and electrical contacts as well as the mechanical support for the sample, and was mounted to a manipulator using tantalum clamps. A pair of Chromel-Alumel thermocouples was spot-welded to the pocket for monitoring the sample temperature. Once under ultrahigh vacuum, the sample surface was cleaned by cycles of $\mathrm{Ar}^{+}$ion sputtering $(2 \mathrm{keV}, 0.6 \mu \mathrm{A}$ beam current, $(1-2) \times 10^{-6}$ Torr, $\left.10 \mathrm{~min}\right)$ and annealing $(950$ $\mathrm{K}, 1 \mathrm{~min}$ ). Surface cleanliness of the sample was checked by AES and SSIMS.

Ethanol (99.5\%) was purchased from Acros and deuterated ethanol $\left(\mathrm{C}_{2} \mathrm{D}_{5} \mathrm{OD},>99 \%\right)$ from CIL. Prior to dosing, these chemicals were degassed by several freeze-pump-thaw cycles. A stainless steel gas doser of 2-mm i.d. was used to introduce them onto the sample in the UHV chamber through a precision leak valve. The purity of the ethanol vapor was checked in situ by mass spectrometry. All doses reported in this study are calibrated back to the background exposure and are expressed in langmuirs $\left(1 \mathrm{~L}=1 \times 10^{-6}\right.$ Torr-s) of exposure at the sample surface. The reading of the gauge was uncorrected for the corresponding sensitivity.

SSIMS measurements were performed using a primary beam of $\mathrm{Ar}^{+}$ions of $2 \mathrm{keV}$ energy to bombard the sample, with the angle between the ion gun and the mass spectrometer fixed at 45 degrees. The ion gun was differentially pumped and operated at a pressure of $\sim 3 \times 10^{-9}$ Torr when SSIMS spectra were recorded. The count rate of secondary ions was maximized by varying the polar angle of ion incidence and by applying a bias voltage $(\sim 20 \mathrm{~V})$ on the sample. The spectra presented in the next section show the typical variation, as a function of the ethanol exposure, in the SSIMS intensities obtained at different $m / e$ in repeated experiments. Except for very small count rates, the measurements taken in these experiments had a repeatability of $\pm 10 \%$ in the signal intensity relative to the $m / e 28$ intensity. Data collection was accomplished using an interface system 


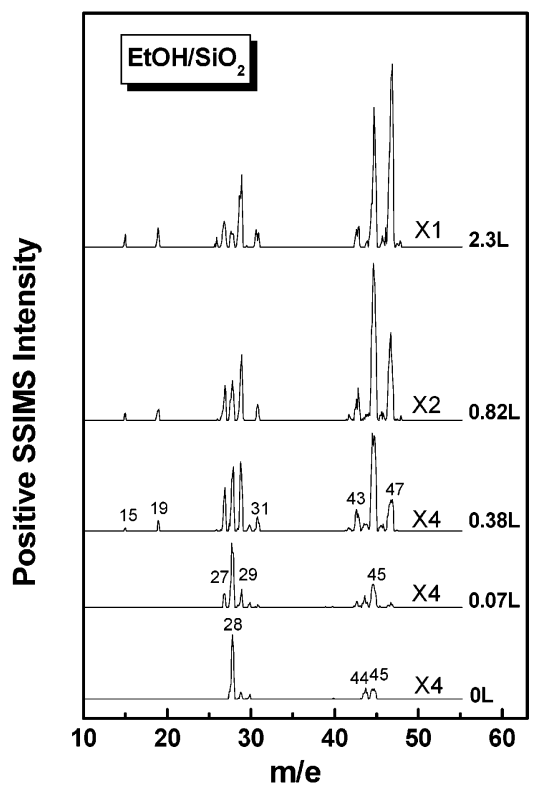

Figure 1. SSIMS spectra of a silicon dioxide surface exposed to the indicated doses of EtOH. All spectra were recorded at $115 \mathrm{~K}$. The spectra were normalized to a constant peak height at $\mathrm{m} / \mathrm{e} 28$.

designed by VG Microtech. Spectra were taken within 3 min of exposure. The typical data collection time was $\sim 6 \mathrm{~min} /$ spectrum.

TPD experiments were conducted with the sample in line of sight of the mass spectrometer (nondifferentially pumped). To preferentially admit gases desorbing directly from the sample surface to the ionizer, this spectrometer was fitted with a stainless steel skimmer with a $0.3-\mathrm{cm}$ diameter opening. For TPD measurements, the sample was placed $\sim 0.1$ in. away from the skimmer. Measurements of the intensities of desorbing species were controlled by interfacing the spectrometer control unit to a personal computer. During each TPD measurement, a linear temperature ramp was applied to the sample and the spectrometer was set to monitor several masses. A heating rate of $\sim 3 \mathrm{~K} / \mathrm{s}$ was used in all TPD experiments.

\section{Results}

The surface reaction of ethanol on the silicon dioxide surface at low temperature was studied using static secondary ion mass spectrometry. The substrate temperature for these SSIMS experiments was maintained at $115 \mathrm{~K}$. Figure 1 displays the SSIMS spectra taken up to $m / e 55$ by exposing several different doses of EtOH to the silicon dioxide surface prepared. A typical SSIMS spectrum measured from the surface after cycles of sample cleaning showed peaks at $m / e$ 28, 40, 44, and 45 . Their relative intensities varied with the preparation/pretreatment procedure of the sample and with the vacuum condition of the analysis system. The m/e 28 peak arose from the sputter desorption of $\mathrm{Si}^{+}$ions from the surface, as supported by the presence in the spectrum of small $\mathrm{m} / \mathrm{e} 29$ and m/e 30 peaks due to the presence of naturally occurring silicon isotopes. Since the sputter yield generally decreases drastically with the layer depth of atoms sputtered from the surface, ${ }^{49-51}$ the large signal, relative to other peaks in the spectrum, observed at $m / e 28$ before $\mathrm{EtOH}$ exposure reveals that the $\mathrm{Si}$ atoms in the sample surface were not completely buried under oxygen atoms. The exposed $\mathrm{Si}$ atoms on the surface may facilitate the reactions of ethanol with silicon dioxide following ethanol adsorption, as will be discussed later.
As shown in Figure 1, the sputter intensity measured at $m / e$ 44 did not increase with the ethanol dose in the low-exposure regime. Instead, its peak area remained at about a constant ratio $(19 \pm 2 \%)$ of the one obtained at m/e 28 . The $m / e 44$ peak thus reflects the characteristics of the sample surface, not of the ethanol reaction on silicon dioxide. It was assigned as due to $\mathrm{SiO}^{+}$ions sputtered from the surface. The absence of SSIMS peaks in Figure 1 from sputtering of low-ionization-potential elements, such as $\mathrm{Na}$ and $\mathrm{K}$, indicates that the impurity level of metals in the sample prepared was below the detection limit of SSIMS, which was in the ppb range under the experimental condition of this study.

3.1. Silanols. The presence of the $m / e 45$ peak in Figure 1 was due to the sputter desorption of $\mathrm{SiOH}^{+}$ions. ${ }^{52,53}$ It indicated that the sample surface prepared in this study contained some amount of hydroxyl species. They were formed on silicon dioxide as a result of dissociative adsorption of water, ${ }^{54,55}$ during sample preparation and in the course of surface cleaning and cooling in the analysis chamber. Similar to the observations made in other studies, ${ }^{54}$ the amount of hydroxyl species formed, as reflected from the m/e 45 SSIMS intensity obtained, depended strongly on the thermal treatment of the sample. Since dehydroxylation through condensation ${ }^{56}$ of geminal and vicinal silanol groups of silicon dioxide proceeds with less energy expenditure required to form siloxane bridges $(\sim 20 \mathrm{~kJ} / \mathrm{mol}$ for geminal groups and $\sim 110 \mathrm{~kJ} / \mathrm{mol}$ for vicinal groups $)^{57,58}$ than that provided in this study during the sample cleaning process (annealing at $950 \mathrm{~K}$ ), the peak observed at $m / e$ e 45 in Figure 1 may be mostly associated with the free silanol groups present on the sample surface prepared.

XPS and SSIMS studies performed by D'Souza et al. ${ }^{59}$ on the silica surface on which the silanol groups were derivatized to produce cyano groups have shown that there is a linear correlation between the surface silanol concentration and $A_{\mathrm{SiOH}+} /$ $A_{\mathrm{Si}+}$, the area ratio of the SSIMS peak for $\mathrm{SiOH}^{+}$ions to the peak for $\mathrm{Si}^{+}$. They also calculated silanol concentrations on silica surfaces on the basis of the intensity of the FTIR absorbance band using the Beer-Lambert law. ${ }^{59}$ According to their calibration table and the $A_{\mathrm{SiOH}+} / A_{\mathrm{Si}+}$ ratio obtained in the SSIMS spectra taken in this study from the clean surface, the silanol concentration on the silicon dioxide surface prepared in this study was $2.6 \pm 0.5 \mathrm{OH} / \mathrm{nm}^{2}$. In comparison, the surface densities of hydroxyl groups for fully hydroxylated silica, ${ }^{60}$ silica heated at $500{ }^{\circ} \mathrm{C}$ in air, ${ }^{59}$ silica heated at $500{ }^{\circ} \mathrm{C}$ in a vacuum, ${ }^{60}$ and silica calcined in air at $1100{ }^{\circ} \mathrm{C}^{59}$ were reported to be 4.9, 2.7, 1.8 , and $0.7 \mathrm{OH} / \mathrm{nm}^{2}$, respectively. The relatively high silanol concentration obtained in this study may be due to the reaction $^{55-56,61}$ of a small amount of water adsorbed on the silicon dioxide surface during cooling to $115 \mathrm{~K}$ after sample cleaning and during data taking.

Hydroxyl groups are usually present on all the surface of solid oxides unless the surface is treated at elevated temperatures ${ }^{62}$ or the dissociative adsorption of water on the oxide surface is a kinetically hindered process. ${ }^{63}$ These groups may behave as hydrogen-bond donors or proton donors (Brønsted acid), depending on their coordination symmetry. ${ }^{64}$ They affect the reactivity of the oxide sample significantly, ${ }^{65}$ as will be discussed later.

3.2. $\mathbf{C}_{2} \mathbf{H}_{3}, \mathbf{C}_{2} \mathbf{H}_{5}$, and $\mathrm{SiH}$. The intensities of the peaks displayed in Figure 1 are normalized to the m/e 28 intensity of each spectrum. The normalization facilitates the deduction of the surface chemistry of ethanol reactions by removing from display the complex effect of the surface work function, which is sensitive to adsorbate coverage, on the SSIMS ion yield. The 
TABLE 1: Assignments of SSIMS Signals Observed in the Spectra Taken from the Silica Surface Exposed to EtOH and d-EtOD, Respectively

\begin{tabular}{clc}
\hline $\begin{array}{c}\text { m/e in d-EtOD } \\
\text { spectrum }\end{array}$ & \multicolumn{1}{c}{ assignment } & $\begin{array}{c}\text { corresponding m/e } \\
\text { in EtOH spectrum }\end{array}$ \\
\hline 28 & $\mathrm{Si}^{+}$ & 28 \\
30 & $\mathrm{CD}_{2} \mathrm{CD}^{+}$ & 27 \\
& $\mathrm{C}_{2} \mathrm{D}_{3}^{+}$ & 27 \\
& $\mathrm{SiD}^{+}$ & 29 \\
32 & $\mathrm{C}_{2} \mathrm{D}_{3} \mathrm{H}_{2}^{+}$ & 29 \\
& $\mathrm{CD}_{2}=\mathrm{CD}_{2}^{+}$ & 28 \\
33 & $\mathrm{C}_{2} \mathrm{D}_{4} \mathrm{H}^{+}$ & 29 \\
& $\mathrm{CD}_{2}=\mathrm{OH}^{+}$ & 31 \\
34 & $\mathrm{CD}_{3} \mathrm{CD}_{2}^{+}$ & 29 \\
& $\mathrm{CD}_{2}=\mathrm{OD}^{+}$ & 31 \\
44 & $\mathrm{SiO}^{+}$ & 44 \\
45 & $\mathrm{CD}_{2}=\mathrm{C}^{+}=\mathrm{OH}^{+}$ & 43 \\
46 & $\mathrm{CD}_{3}-\mathrm{C}^{+} \mathrm{O}^{+}$ & 43 \\
& $\mathrm{CD}_{2}=\mathrm{C}^{+}=\mathrm{OD}^{+}$ & 43 \\
& $\mathrm{SiOD}^{+}$ & 45 \\
49 & $\mathrm{CD}_{3}-\mathrm{CD}^{+} \mathrm{OH}^{+}$ & 45 \\
50 & $\mathrm{CD}_{3}-\mathrm{CD}^{+} \mathrm{OD}^{+}$ & 45 \\
& $\mathrm{C}_{2} \mathrm{D}_{5} \mathrm{O}^{+}$ & 45 \\
52 & $\mathrm{CD}_{3} \mathrm{CD}_{2} \mathrm{OH}_{2}$ & 47 \\
53 & $\mathrm{CD}_{3} \mathrm{CD}_{2} \mathrm{ODH}^{+}$ & 47 \\
& $\mathrm{CD}_{3} \mathrm{CD}_{2} \mathrm{OHD}^{+}$ & 47 \\
54 & $\mathrm{CD}_{3} \mathrm{CD}_{2} \mathrm{OD}_{2}{ }^{+}$ & 47 \\
& &
\end{tabular}

sputter yield of $\mathrm{Si}^{+}$(m/e 28) ions from a clean sample surface was very small. Upon adsorption of ethanol, the signal intensities of all positive ions, including $\mathrm{Si}^{+}$, increased because of the increase in the surface work function. ${ }^{66} \mathrm{The}^{\mathrm{Si}}{ }^{+}$ion intensity then decreased as the surface was covered by ethanol at high exposures.

As shown in the figure, the $m / e$ 27, 29, and 45 signal intensities increased substantially, in comparison to the $m / e 28$ intensity, when EtOH of as small as $0.07 \mathrm{~L}$ exposure was dosed to the silicon dioxide surface at $115 \mathrm{~K}$. Further increasing the exposure to $0.38 \mathrm{~L}$ caused the rise of major SSIMS signals at $m / e 43$ and 47 , in addition to the large increase in intensity observed at $m / e 27,29$, and 45 and to the growth of small peaks at $m / e 19$ and 31 . They indicated that ethanol may decompose to a significant extent upon adsorption on the metal-free silicon dioxide surface at a low substrate temperature of $115 \mathrm{~K}$.

The increase in the SSIMS intensity at m/e 29 is attributed in part to the production of ethyl species from ethanol reactions on the sample surface. The m/e 27 peak may be associated with the further dehydrogenation of ethyl on the surface to form $\mathrm{C}_{2} \mathrm{H}_{3}{ }^{+}$. In addition, it may be due to ethylene, which is formed on the surface from dehydroxylation of ethanol, ${ }^{39,67,68}$ losing a hydrogen atom during sputtering to yield $\mathrm{CH}_{2} \mathrm{CH}^{+}$.

These peak assignments, summarized in Table 1, are supported by results obtained from studies on the deuterium-labeled reactions of ethanol on silicon dioxide. As elaborated later, the details of the ethanol reaction processes on silicon dioxide may also be deduced from a cross examination of the spectra taken from the sample surfaces exposed to deuterated and nondeuterated (normal) ethanols, respectively. Shown in Figure 2 are the SSIMS spectra taken from the silicon dioxide surface exposed at $115 \mathrm{~K}$ to the indicated doses of deuterated ethanol, $\mathrm{C}_{2} \mathrm{D}_{5} \mathrm{OD}$ (d-EtOD). At the d-EtOD exposure of $0.12 \mathrm{~L}$, there was a substantial increase in the SSIMS intensity observed at $m / e$ 30, as compared to its intensity obtained before exposure. Major SSIMS signals were also detected at m/e 34 and $m / e 46$. In comparison to the SSIMS spectra taken from the sample surface exposed to EtOH (Figure 1), it indicated that the m/e 30 peak was related with the sputtering of $\mathrm{C}_{2} \mathrm{D}_{3}{ }^{+}$ions, the deuterated counterpart of the m/e 27 species appearing in Figure

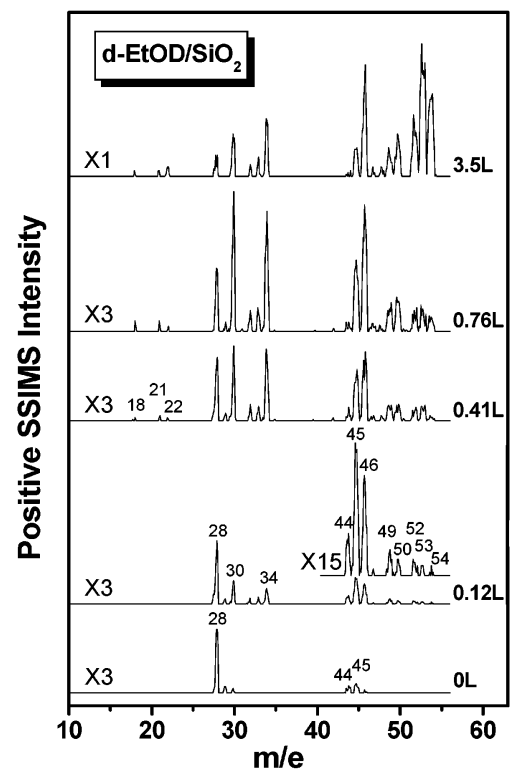

Figure 2. SSIMS spectra of a silicon dioxide surface exposed to the indicated doses of d-EtOD. All spectra were recorded at $115 \mathrm{~K}$. The spectra were normalized to a constant peak height at $\mathrm{m} / \mathrm{e} 28$.

1 , and the m/e 34 peak with that of deuterated ethyl ions. The rise of small peaks at $m / e 33$ and $m / e 32$ in Figure 2 may be ascribed in part to isotope exchange of $\mathrm{D}$ from $\mathrm{CD}_{2} \mathrm{CD}_{3}{ }^{+}$with $\mathrm{H}$ on the surface. The occurrence of the H/D exchange reaction on the surface at the low d-EtOD exposure of $0.12 \mathrm{~L}$ suggests that a noticeable amount of hydrogen atoms was present on the sample surface prepared in this study before ethanol exposure. In fact, the SSIMS intensity of the m/e 29 peaks shown in Figure 2 exceeds the expected isotope abundance of ${ }^{29} \mathrm{Si}$, supporting the presence of $\mathrm{H}$ on the silicon dioxide surface exposed to deuterated ethanol.

New $\mathrm{Si}-\mathrm{H}$ bonds were also formed when the sample was exposed to $\mathrm{EtOH}$. The presence of $\mathrm{H}$ atoms on the sample surface from $\mathrm{EtOH}$ dissociation may cause the $m / e 27$ intensity in Figure 1 to be lower than the m/e 29 intensity, whereas the presence of $\mathrm{D}$ atoms from $\mathrm{d}-\mathrm{EtOD}$ dissociation may cause the m/e 30 intensity in Figure 2 to be higher than the m/e 34 intensity. When EtOH was exposed, the sputtering of $\mathrm{SiH}^{+}$ augmented the peak signal at m/e 29, to which ethyl ions contributed, and its resulting peak intensity was slightly higher than the one measured at m/e 27 (Figure 1). On the other hand, when d-EtOD was exposed, $\mathrm{H}$ atoms originally present on the sample surface were gradually consumed, such as by H/D exchange and protonation of decomposition products, at increasing doses. At the same time, the decomposition of d-EtOD on silicon dioxide and the isotope exchange process led to the accumulation of D atoms on the surface. It caused the sputter yield of $\mathrm{SiD}^{+}$ions to increase, which contributed to the SSIMS intensity measured at the same $m / e$ as that for $\mathrm{C}_{2} \mathrm{D}_{3}{ }^{+}$ions, instead of for ethyl ions. As shown in Figure 2, the additional contribution from the $\mathrm{SiD}^{+}$ions to the peak intensity measured at $m / e 30$ and the decrease in contribution to the $m / e 34$ intensity due to H/D exchange may then cause the m/e 30 intensity to be slightly higher than the intensity obtained at m/e 34 in the low d-EtOD exposure regime of below $0.76 \mathrm{~L}$.

The reverse in relative sputter intensities measured at the masses for $\mathrm{C}_{2} \mathrm{X}_{3}{ }^{+}$and $\mathrm{C}_{2} \mathrm{X}_{5}{ }^{+}$ions $(\mathrm{X}=\mathrm{D}$ or $\mathrm{H})$ shown in Figures 1 and 2 thus supports the argument that, in addition to those already existing before exposure, new $\mathrm{Si}-\mathrm{X}$ bonds may be formed on the silicon dioxide surface exposed to ethanol. The sputtering of $\mathrm{SiX}^{+}(\mathrm{X}=\mathrm{D}$ or $\mathrm{H})$ ions disclosed in these 
two figures, however, could result from the recombination reactions, occurring in the space above the surface, of the desorbed $\mathrm{Si}$ and $\mathrm{X}$ atoms which were emitted from the sample surface via certain correlated collision sequences. ${ }^{69,70}$ To confirm that the observed $\mathrm{SiX}^{+}$ion sputtering was mainly due to the formation of $\mathrm{Si}-\mathrm{X}$ bonds on the surface exposed to ethanol, estimation of the contribution of $\mathrm{SiX}^{+}$ions to the intensities measured at m/e 29 in Figure 1 and at m/e 30 in Figure 2 was performed. The estimation was based on the assumption that the $m / e$ 32, m/e 33, and $m / e 34$ peaks observed in Figure 2 were contributed from ethyl ions alone and that the relative abundance of $\mathrm{C}_{2} \mathrm{X}_{3}$ and $\mathrm{C}_{2} \mathrm{X}_{5}$ remained about the same in the ethanol exposure range between $0.38 \mathrm{~L}$ and $0.41 \mathrm{~L}$. The areas of the $m / e 27$ and $m / e 29$ peaks obtained at $0.38 \mathrm{~L} \mathrm{EtOH}$ exposure (Figure 1) and of the $m / e$ 30, m/e 32, m/e 33, and $m / e$ 34 peaks measured at $0.41 \mathrm{~L} \mathrm{~d}$-EtOD exposure (Figure 2) were each calculated. The difference and reversal in the intensities observed in Figures 1 and 2 between $\mathrm{C}_{2} \mathrm{X}_{3}$ and $\mathrm{C}_{2} \mathrm{X}_{5}$ were then used to estimate their contributions from $\mathrm{SiX}^{+}$ion sputtering.

The results indicated that $\mathrm{SiD}^{+}$ions sputtered from the surface contributed significantly to the $m / e 30$ signal intensity $(\sim 51 \%)$ shown in Figure 2 at $0.41 \mathrm{~L}$ exposure, after the contribution due to the presence of residual ${ }^{29} \mathrm{SiH}$ species on the surface was removed. A large contribution of $\sim 32 \%$ was obtained for $\mathrm{SiH}^{+}$ions to the m/e 29 SSIMS intensity shown in Figure 1 at $0.38 \mathrm{~L}$ exposure. Comparison with their corresponding $\mathrm{Si}^{+}$ SSIMS intensities revealed that these calculated $\mathrm{SiX}^{+}$intensities were significantly higher than the predicted values for ion formation via space recombination, ${ }^{69,70}$ if the ionization probabilities of $\mathrm{Si}$ and $\mathrm{SiH}$ during sputtering were assumed similar. Therefore, an appreciable number of $\mathrm{Si}-\mathrm{H}$ bonds were formed on silicon dioxide during ethanol decomposition on the surface. The observation of the formation of new $\mathrm{Si}-\mathrm{H}$ bonds from hydrogen atoms produced during ethanol dissociation on silicon dioxide is in agreement with conclusions from an earlier report that hydrogen atoms are highly mobile in the oxide and diffuse through it toward the silicon-silicon oxide interface where they create defects. ${ }^{24}$

The presence of hydrogen on the sample surface may also facilitate the abstraction of $\mathrm{H}$ (or D) atoms by ethylene during its surface ionization before sputter desorption. The H-ethylene adduct contributes to the sputter yields measured at m/e 29 $\left(\mathrm{C}_{2} \mathrm{H}_{4} \mathrm{H}^{+}\right)$shown in Figure 1 and at m/e $33\left(\mathrm{C}_{2} \mathrm{D}_{4} \mathrm{H}^{+}\right)$and 34 $\left(\mathrm{C}_{2} \mathrm{D}_{4} \mathrm{D}^{+}\right)$in Figure 2. Its contribution was small, however, in comparison to the contribution from ethyl species. It is expected that at low exposures of d-EtOD, the surface is populated with more hydrogen atoms than deuterium atoms. The m/e 33 peak should then have a higher signal intensity than the $m / e 34$ peak observed in Figure 2 if the sputter desorption of ethylene via hydrogen acquisition dominates the peak intensities obtained. The fact that the SSIMS intensity measured at m/e 34 was significantly higher than that obtained at m/e 33 indicates that it is the sputtering of ethyl species which dominates. Ethyl species thus also dominates the contribution to the $m / e 29$ intensity shown in Figure 1.

The results also confirm that on silicon dioxide, the $\mathrm{Et}-\mathrm{OH}$ bond may be cleaved and ethanol may decompose to the extent that ethyl species are produced. As shown in Figures 1 and 2, the abundance of $\mathrm{C}_{2} \mathrm{H}_{3}$ and $\mathrm{C}_{2} \mathrm{D}_{3}$ on the surfaces reacted with EtOH and d-EtOD, respectively, reveals that the $\mathrm{C}-\mathrm{X}(\mathrm{X}=\mathrm{D}$ or $\mathrm{H}$ ) bond in the ethyl group may be also disrupted during ethanol reaction with silicon dioxide. The $\mathrm{H}$ (or D) atoms produced from the disruption may then aid in the formation of the $\mathrm{Si}-\mathrm{H}$ bonds.
3.3. $\mathrm{C}_{2} \mathrm{H}_{5} \mathrm{O}, \mathrm{C}_{2} \mathrm{H}_{3} \mathrm{O}, \mathrm{CH}_{3} \mathrm{O}, \mathrm{SiOH}$, and $\mathrm{SiOEt}$. The increase in the SSIMS intensity observed at $m / e$ in Figure 1 after ethanol exposure may be attributed to the $\mathrm{SiOH}$ and $\mathrm{EtO}$ species generated from ethanol reactions on the silicon dioxide surface. In addition, abstraction of $\mathrm{H}$ by the surface from the adsorbed ethanol may lead to the formation of a stable oxonium species, $\mathrm{CH}_{3}-\mathrm{CH}=\mathrm{OH}^{+}, 67$ which may also contribute to the intensity increase observed at $m / e$ 45. The abstraction of $\mathrm{H}$ by the adsorbed ethanol molecule from the silicon dioxide surface during sputter desorption, on the other hand, facilitates the detection of ethanol at $m / e 47$ as $\mathrm{EtOH}_{2}{ }^{+}$.

Further dehydrogenation of EtO on the surface or during sputtering may cause the m/e 43 peak to rise in Figure 1 . The $m / e 43$ species may also be brought about by the additional loss of hydrogen from the m/e 45 oxonium species to form $\mathrm{C}_{2} \mathrm{H}_{3} \mathrm{O}^{+}$. The signal observed at $m / e$ in Figure 1 may be generated by elimination of $\mathrm{CH}_{3}$ via $\alpha$-cleavage from ethanol, forming another stable oxonium species $\mathrm{CH}_{2}=\mathrm{OH}^{+}$(m/e 31) during sputtering. ${ }^{71}$ It is a mass signature of primary alcohols. ${ }^{72}$

3.3.1. H Attachment to Ethanol. The attributions made above are supported by the SSIMS spectra taken from the silicon dioxide surface exposed to deuterated ethanol. At the d-EtOD exposure of $0.12 \mathrm{~L}$, the SSIMS spectrum obtained, shown in Figure 2, exhibited a large increase in intensity at $m / e \quad 45$ and $m / e 46$, in addition to the rise of sputter intensities at $m / e 49$, $50,52,53$, and 54 . The $m / e 54$ peak corresponds to the peak observed at m/e 47 in Figure 1. It arose from the sputter desorption of the d-EtOD molecule from the sample in the form of $\mathrm{d}-\mathrm{EtOD}_{2}{ }^{+}$after acquiring a $\mathrm{D}$ atom from the silicon dioxide surface. Since at the low d-EtOD exposure of $0.12 \mathrm{~L}$ the sample surface was populated with $\mathrm{H}$ species, as discussed above, the $\mathrm{d}$-EtOD molecule on the surface may acquire a $\mathrm{H}$ atom, instead, from the surface during its sputter desorption. The $m / e 53$ (d$\mathrm{EtODH}^{+}$) peak was thus observed and its signal intensity at low exposures was larger than the one measured at $m / e 54$.

3.3.2. $\mathrm{SiO}-\mathrm{H}$ Bonding. The presence of a relatively large peak at $m / e 52$, in comparison to the $m / e 53$ and $m / e 54$ peak intensities, in Figure 2 is very interesting. The much smaller signal intensity observed at m/e 46 than at $m / e 47$ in Figure 1 excludes the possibility that deuterated ethanol was sputtered mainly in the form of $\mathrm{d}-\mathrm{EtOD}^{+}(\mathrm{m} / \mathrm{e}$ 52). The smaller peaks observed at m/e 33 and 32 than the one at m/e 34 in Figure 2 reveal that $H / D$ exchange of adsorbed species with surface $H$ atoms is kinetically suppressed to some extent. The $m / e 52$ species present in a relatively large amount were thus not produced mainly from H/D exchange of the m/e 54 or $m / e 53$ species. The relatively large SSIMS intensity observed at $m / e$ 52 also does not warrant the formation of the m/e 52 species via simultaneous acquisition of two $\mathrm{H}$ atoms from the sample surface by the $m / e 50$ species during sputter desorption either. Therefore, a species in the form of $\mathrm{C}_{2} \mathrm{D}_{5} \mathrm{HO}$ (i.e., d-EtOD with one $\mathrm{D}$ being replaced by $\mathrm{H}$ ) had to be present on the surface, which then acquired a $\mathrm{H}$ atom during sputtering from the surface to desorb as $m / e 52$.

There are in total six deuterium atoms in ethanol which could undergo substitution reactions to form $\mathrm{C}_{2} \mathrm{D}_{5} \mathrm{HO}$. The similarities in chemical reactivity of the $\mathrm{C}-\mathrm{D}$ bonds in the ethoxy group of deuterated ethanol and in thermodynamic and chemical stability of the various deuterated forms of ethoxy, $\mathrm{C}_{2} \mathrm{D}_{x} \mathrm{H}_{y} \mathrm{O}$ ( $x=0-5$ and $y=5-x$ ), would ensure the formation of various deuterated ethoxy and have given rise to the appearance of a few peaks in the SSIMS spectrum at $m / e$ lower than 52, should substitution reactions occur on ethoxy. The absence of the $m / e$ 


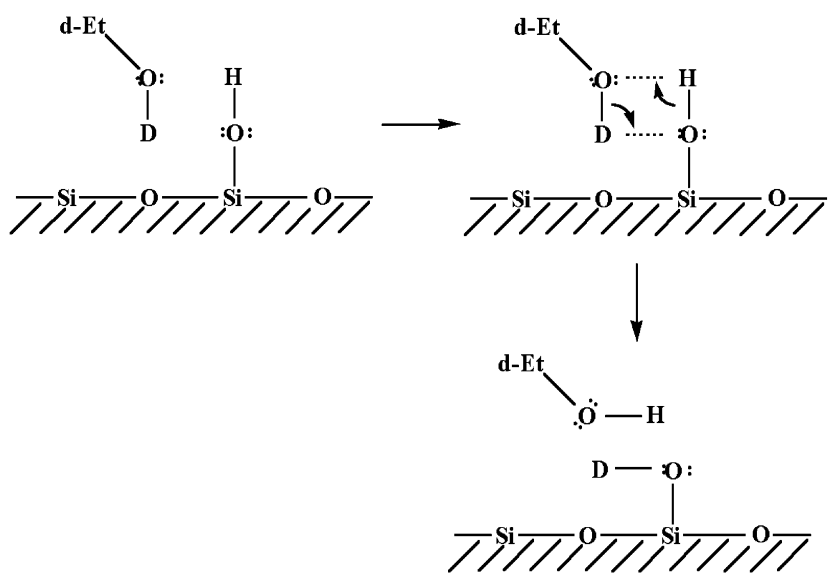

Figure 3. Illustration of a possible substitution reaction via hydrogen bonding between silanol on the surface and the hydroxyl group of ethanol.

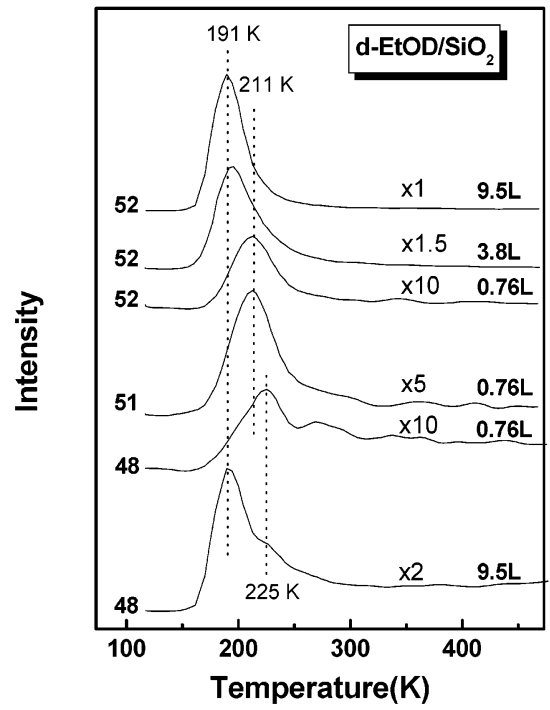

Figure 4. TPD profiles for d-EtOD adsorbed on silicon dioxide at $115 \mathrm{~K}$. The profiles were taken at indicated $\mathrm{m} / \mathrm{e}$ and doses. The heating rate was about $3 \mathrm{~K} / \mathrm{s}$.

51 peak in the SSIMS spectra displayed in Figure 2 suggests that it is the hydroxyl hydrogen which undergoes substitution.

Instead of H/D exchange between the surface $\mathrm{H}$ atoms and the ethanol D atoms on hydroxyls, which was kinetically suppressed to some extent as pointed out earlier, such a substitution reaction was facilitated by the presence of silanols on the sample surface. As discussed before, the presence of the $m / e 45$ peaks with distinctive intensities at $0 \mathrm{~L}$ exposure in Figures 1 and 2 indicates that a discernible amount of silanols were present on the silicon dioxide surface prior to ethanol exposure. The substitution reaction may take place via hydrogen bonding between the silanol on the surface and the hydroxyl group of ethanol, ${ }^{73,74}$ as illustrated in Figure 3. It leads to the production of $\mathrm{C}_{2} \mathrm{D}_{5} \mathrm{HO}$ (d-EtOH) and deuterated silanol ( $\mathrm{SiOD}$ ). The production of $\mathrm{SiOD}$ contributes in part to the large increase in SSIMS intensity observed at $m / e 46$ in Figure 2 at increasing exposures

To obtain spectral evidence supporting the argument about the presence of $\mathrm{d}-\mathrm{EtOH}$ on the sample surface exposed to d-EtOD, temperature-programmed desorption experiments were conducted. Presented in Figure 4 are TPD spectra taken from the sample surface exposed to d-EtOD at $115 \mathrm{~K}$. These experiments were performed with an electron impact device placed in front of the quadrupole mass analyzer for ionizing particles which thermally desorbed from the sample surface. At $0.76 \mathrm{~L}$ d-EtOD exposure, m/e 52 (d-EtOD) was observed to desorb in the substrate temperature range between 175 and 250 $\mathrm{K}$. Its desorption peaked at $211 \mathrm{~K}$. The TPD profiles obtained at $m / e 51$ resembled closely to the one obtained at $m / e$ 52. Since d-EtOD has no fragments with the m/e of 51, excluding the possibility of detecting the product from its dissociation in the TPD ionizer at $m / e 51$, the $m / e 51$ species observed must desorb from the sample surface. The larger area measured under the $m / e 51$ TPD peak than that under the $m / e 52$ peak, as shown in Figure 4, is in accord with the presence of more silanols $(\mathrm{SiOH})$ on the surface at low exposures. The TPD data thus support that d-EtOH $(m / e$ 51) was produced on the sample surface exposed to d-EtOD. The reactions of normal ethanol on the sample should thus also involve the formation of the EtO-H and $\mathrm{SiO}-\mathrm{H}$ bonds.

3.3.3. $\mathrm{CH}_{3}-\mathrm{CH}=\mathrm{OH}^{+}$. Just as the contribution of $\mathrm{EtO}^{+}$to the m/e 45 SSIMS intensity observed in Figure 1, both the $\mathrm{d}-\mathrm{EtOD}$ and d-EtOH molecules present on the sample surface contributed to the signal intensity observed at $m / e 50$ in Figure 2 after the exposed ethanol lost its hydroxyl hydrogen before registering itself in the mass spectrometer as d-EtO ${ }^{+}$. Another species, $\mathrm{SiOH}^{+}$, contributing to the $m / e 45$ intensity observed in Figure 1, had a corresponding contribution, when deuterated ethanol was exposed, from $\mathrm{SiOD}^{+}$to the m/e 46 intensity shown in Figure 2, as discussed above. The third contribution to the m/e 45 signal intensity in Figure 1, assigned as due to the production of a stable oxonium species, $\mathrm{CH}_{3}-\mathrm{CH}=\mathrm{OH}^{+}$, was supported by the observation of an additional signal at $m / e$ in Figure 2. The deuterated counterpart of this stable oxonium species takes the form of $\mathrm{CD}_{3}-\mathrm{CD}=\mathrm{OD}^{+}$and should contribute to the m/e 50 SSIMS intensity observed in Figure 2. This species is formed via disruption of a $\mathrm{C}-\mathrm{D}$ bond in the adsorbed ethanol. The presence of both d-EtOD and d-EtOH on the surface, after the exposed deuterated ethanol undergoing substitution reactions via hydrogen bonding, thus leads to the formation of $\mathrm{CD}_{3}-\mathrm{CD}=\mathrm{OD}^{+}$(m/e 50) and $\mathrm{CD}_{3}-\mathrm{CD}=\mathrm{OH}^{+}$ (m/e 49), respectively.

As shown in Figure 2, the two pairs of SSIMS peaks, one present at $\mathrm{m} / \mathrm{e} 49$ and $\mathrm{m} / \mathrm{e} 52$ and the other at $\mathrm{m} / \mathrm{e} 50$ and $\mathrm{m} / \mathrm{e}$ 53 , display similar intensity ratios at each ethanol dose in the low-exposure regime. The peaks observed at $\mathrm{m} / \mathrm{e} 49$ and 52 may be mainly due to surface reactions originating from an identical compound, $\mathrm{d}-\mathrm{EtOH}$, and the peaks at $\mathrm{m} / \mathrm{e} 50$ and 53 originating mainly from d-EtOD, as discussed above and depicted in the equations below.

$$
\begin{aligned}
& \text { d-EtOH }{ }_{2}^{+} \stackrel{\text { H attachment }}{\longleftarrow} \text { d-EtOH } \stackrel{\mathrm{C}-\text { D bond disruption }}{\longrightarrow} \\
& \text { m/e } 52 \longleftarrow \text { m/e } 51 \\
& \mathrm{CD}_{3}-\mathrm{CD}=\mathrm{OH}^{+} \\
& \text {m/e } 49 \\
& \underset{m / e}{\mathrm{~d}-\mathrm{EtODH}^{+}} \stackrel{\text { H attachment }}{\stackrel{\mathrm{H}-\mathrm{EtOD}}{m / e} 52} \stackrel{\mathrm{C}-\mathrm{D} \text { bond disruption }}{\longrightarrow} \\
& \mathrm{CD}_{3}-\mathrm{CD}=\mathrm{OD}^{+} \\
& \text {m/e } 50
\end{aligned}
$$

The similarity thus supports that the m/e 50 SSIMS intensity was mainly contributed from $\mathrm{CD}_{3}-\mathrm{CD}=\mathrm{OD}^{+}$ions. The contribution of ${\mathrm{d}-\mathrm{EtO}^{+}}^{+}$to the $m / e 50$ peak intensity shown in Figure 2, and thus of $\mathrm{EtO}^{+}$to the m/e 45 intensity in Figure 1, is minor. This conclusion is in agreement with the results obtained from ab initio calculations, ${ }^{75}$ which showed that out 


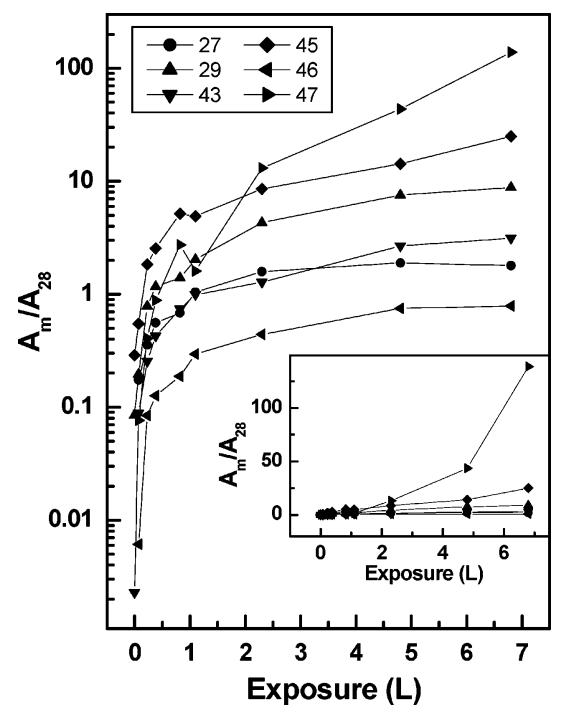

Figure 5. Ratios, displayed on the log scale, of peak areas obtained at $m / e 27,29,43,45,46$, and 47 to the area of the m/e 28 peak in the SSIMS spectra of a silicon dioxide surface exposed to EtOH. All measurements were taken at $115 \mathrm{~K}$. Inset: Same ratios displayed on the linear scale.

of the three stable isomers of $\mathrm{C}_{2} \mathrm{H}_{5} \mathrm{O}^{+}$(i.e., $\mathrm{EtO}^{+}$), the 1-hydroxylethyl $\left(\mathrm{CH}_{3} \mathrm{CHOH}^{+}\right)$cation was more stable than the ethoxy and 2-hydroxyethyl $\left(\mathrm{CH}_{2} \mathrm{CH}_{2} \mathrm{OH}^{+}\right)$cations.

3.3.4. EtO-Si Bonding. The minimal contribution of d-EtO ${ }^{+}$ ions to the m/e 50 peak intensity shown in Figure 2 does not imply that the EtO population on the silicon dioxide surface exposed to ethanol at $115 \mathrm{~K}$ is negligible. On the contrary, it may constitute one of the major products yielded from ethanol decomposition on the surface. Early studies of ethanol reactions occurring at different temperatures above $180{ }^{\circ} \mathrm{C}^{39,40,67}$ on the silica surface have found that ethoxy was formed on the surface, with a density as high as twice the hydroxyl surface density. ${ }^{67}$ Its decomposition was believed to produce ethylene detected at high substrate temperatures. ${ }^{40}$ For the methanol exposure to silica, methoxy groups were also formed on the surface. ${ }^{76}$ The lack of the $\mathrm{EtO}^{+}$contribution to SSIMS signals observed in Figures 1 and 2 may be due to the energetics associated with the homolysis of the EtO-Si bond following ion irradiation. The energy of $1.712 \mathrm{eV}^{77,78}$ is released when an electron is added to ethoxy to form $\mathrm{EtO}^{-}$, whereas the energy of $10.29 \mathrm{eV}^{79}$ is required if the outermost electron is to be removed from ethoxy to form $\mathrm{EtO}^{+}$. The chance of detecting $\mathrm{EtO}^{+}$in the positive SSIMS is thus greatly reduced.

Peak area analysis revealed that ethoxy was present on the sample surface exposed to ethanol at $115 \mathrm{~K}$. Displayed in Figure 5 is the variation in the peak area of some major SSIMS peaks obtained from increasing doses of EtOH. As shown in the figure, the areas of all peaks increase rapidly with the ethanol coverage in the low-exposure regime of less than $\sim 0.5 \mathrm{~L}$. At higher exposures, the rate of increase diminishes in the log scale until the exposure of $\sim 2 \mathrm{~L}$, after which the rates for all signals except m/e 47 become similar and small. The m/e 47 peak area, however, continues to increase with the ethanol exposure. The continuous, large increase in the SSIMS intensity for $m / e 47$ $\left(\mathrm{EtOH}_{2}{ }^{+}\right)$at increasing ethanol exposures, coupled with the shift of the TPD peak to lower temperatures observed in Figure 4 for $m / e 52$ (d-EtOD), shows that at high exposures, ethanol physisorbs in the molecular form on the silicon dioxide surface at $115 \mathrm{~K}$ via hydrogen bonding. Similar observations were also obtained from FTIR studies of ethanol on the silica surface. ${ }^{80}$
If both the $m / e 46$ and $m / e 47$ peaks in Figure 1 result from ethanol molecules adsorbed on the surface, one would expect to observe similar dependence of their peak areas on the exposure. The absence in Figure 5 of a continuous, large increase in the $m / e 46$ SSIMS peak area with the exposure indicates that the m/e 46 peak observed in Figure 1 cannot be attributed to ethanol present in the molecular form on the surface. It is thus postulated that ethoxy groups were present on the sample surface exposed to ethanol at $115 \mathrm{~K}$ and bonded to the silicon atoms exposed to vacuum. Ion bombardment initiated collision cascades leading to the breakage of the EtO-Si bond. The ethoxy species produced was then protonated to contribute to the $m / e$ $46\left(\mathrm{EtOH}^{+}\right)$signal observed in Figure 1. The change in the SSIMS peak area for $m / e 46$ with the exposure thus follows the same pattern, as shown in Figure 5, as those displayed by the surface species produced by ethanol reactions on silicon dioxide.

Once formed, the ethoxy groups on silicon atoms can interact and form a hydrogen bond through its oxygen atom, fixed at a distance close to the surface, with a neighboring isolated $\mathrm{OH}$ group, producing a stable associated species. ${ }^{39}$ Infrared studies of the reaction of methanol on silica have also established such interaction to be predominant between surface silanols and the adsorbed species. ${ }^{73}$ Ethoxy may thus be present on the silicon dioxide surface with a notable density following ethanol reactions. ${ }^{67}$

3.3.5. Oxygen-Protonated Ketene and Acetyl. In addition to the contribution from $\mathrm{SiOD}^{+}$, the $m / e 46$ peak intensity observed in Figure 2 is also ascribed to the sputtering of the deuterated counterparts of the species which give rise to the m/e 43 peak shown in Figure 1. As stated before, these m/e 43 species were formed by the m/e 45 oxonium species losing two hydrogen atoms during their further reaction with the silicon dioxide surface. For the reaction of d-EtOD on silicon dioxide, the loss of two deuterium atoms from the m/e 50 deuterated oxonium species, $\mathrm{CD}_{3}-\mathrm{CD}=\mathrm{OD}^{+}$, yields the $m / e 46$ species, which may be present in two different forms, that is, oxygen-protonated ketene and acetyl. Similarly, the m/e 49 deuterated oxonium species, $\mathrm{CD}_{3}-\mathrm{CD}=\mathrm{OH}^{+}$, can forfeit two hydrogen or deuterium atoms during its reactions with the silicon dioxide surface. As discussed below, it may give rise to the formation of ketene $\left(\mathrm{CD}_{2}=\mathrm{C}=\mathrm{OH}^{+}, m / e\right.$ 45) and acetyl $\left(\mathrm{CD}_{3}-\mathrm{C} \equiv \mathrm{O}^{+}\right.$, m/e 46) species.

The presence of silanol groups on the bare sample surface, before the exposure of deuterated ethanol, resulted in a significant contribution of $\mathrm{SiOH}^{+}$to the signal intensity measured at m/e 45 at low d-EtOD exposures. It caused the $m / e 45$ intensity to be higher than the $m / e 46$ intensity observed at $0.12 \mathrm{~L}$ exposure in Figure 2. As the relative concentration of surface $\mathrm{H}$ atoms was decreased with increasing d-EtOD exposures, less d-EtOH was produced. This in turn caused the relative surface concentrations of $\mathrm{d}_{-} \mathrm{EtOH}_{2}{ }^{+}(\mathrm{m} / \mathrm{e} 52)$, $\mathrm{CD}_{3}-\mathrm{CD}=\mathrm{OH}^{+}$(m/e 49), and $\mathrm{CD}_{2}=\mathrm{C}=\mathrm{OH}^{+}$(m/e 45) to diminish, when they are compared to the concentrations of $\mathrm{d}-\mathrm{EtOD}_{2}{ }^{+}$(m/e 54), $\mathrm{CD}_{3}-\mathrm{CD}=\mathrm{OD}^{+}\left(m / e\right.$ 50), and $\mathrm{CD}_{2}=\mathrm{C}=$ $\mathrm{OD}^{+}$(m/e 46), respectively. The fact that the ratio, $I_{46} / I_{45}$, of the $m / e 46$ SSIMS intensity to the $m / e 45$ intensity is higher than the $I_{50} / I_{49}$ and $I_{54} / I_{52}$ ratios supports that there is an additional contribution to the m/e 46 intensity from $\mathrm{SiOD}^{+}$ions. The production of $\mathrm{SiOH}$ species during $\mathrm{EtOH}$ reactions with silicon dioxide is again confirmed.

The observation of two major peaks at $\mathrm{m} / \mathrm{e} 45$ and $\mathrm{m} / \mathrm{e} 46$ and the alteration with d-EtOD exposure of their relative signal intensities shown in Figure 2 confirm the contributions of both 
oxygen-protonated ketene and acetyl to the signal intensity observed at m/e 43 in Figure 1 when $\mathrm{EtOH}$ is exposed. Among them, acetyl is thermodynamically favored by as much as 35 $\mathrm{kcal} / \mathrm{mol},{ }^{81}$ although surface ionization during sputtering may not necessarily yield thermodynamically favored species. ${ }^{82}$ The above-mentioned observation also supports the contribution of the oxonium species $\mathrm{CH}_{3}-\mathrm{CH}=\mathrm{OH}^{+}$to the $m / e 45$ intensity, since both ketene and acetyl are produced from the $\mathrm{m} / \mathrm{e} 45$ oxonium species.

3.3.6. $\mathrm{CD}_{2}=\mathrm{OH}^{+}$. Elimination of methyl via $\alpha$-cleavage from deuterated ethanol yielded the deuterated counterparts of the species which contributed to the m/e 31 signal shown in Figure 1. The loss of $\mathrm{CD}_{3}$ from d-EtOD yielded a stable oxonium, $\mathrm{CD}_{2}=\mathrm{OD}^{+}$, which, together with ethyl species, contributed to the signal intensity observed at m/e 34 in Figure 2. On the basis of the discussion above, d-EtOH was also present on the surface when d-EtOD was exposed to the sample. The breakage of the $\mathrm{C}-\mathrm{C}$ bond from d-EtOH produced another oxonium, $\mathrm{CD}_{2}=$ $\mathrm{OH}^{+}$, which contributed to the signal intensity observed at $\mathrm{m} / \mathrm{e}$ 33. The elimination of methyl from ethanol also led to the presence of the m/e $15\left(\mathrm{CH}_{3}{ }^{+}\right)$peak in the SSIMS spectrum shown in Figure 1 and of the m/e $18\left(\mathrm{CD}_{3}{ }^{+}\right)$peak shown in Figure 2 at high exposures. They all suggest that the $\mathrm{C}-\mathrm{C}$ bond in ethanol may be disrupted.

In contrast to the higher intensity for the low-mass partner observed at $0.12 \mathrm{~L}$ exposure of d-EtOD for the pairs of peaks ( $m / e 45$ vs $m / e 46, m / e ~ 49$ vs $m / e 50$, and $m / e ~ 52$ vs $m / e 53$ ) shown in the high mass region in Figure 2, the SSIMS intensity obtained at $m / e 33$ was significantly smaller than that of $m / e$ 34. As discussed above, the high-mass partners of these pairs of peaks may all originate from surface reactions of d-EtOD and the low-mass one from that of d-EtOH. The previous discussion also indicates that the surface concentration of $\mathrm{d}-\mathrm{EtOH}$ is higher than $\mathrm{d}-\mathrm{EtOD}$ at $0.12 \mathrm{~L} \mathrm{~d}$-EtOD exposure. The observation of a smaller peak at m/e 33 than the peak at $m / e 34$ thus indicates that, when d-EtOD is exposed, ethyl species and its product from H/D exchange contribute substantially more to the intensities measured at m/e 33 and m/e 34 than the oxonium species. This conclusion is also consistent with the intensity difference displayed in Figure 1 between m/e 29 and m/e 31 .

3.4. Formation of Acetaldehyde. The sputtering of $\mathrm{CH}_{3}-\mathrm{CH}=\mathrm{OH}^{+}$ions, which contribute to the m/e 45 peak shown in Figure 1, is not mainly due to ethanol losing one of its ethyl hydrogens during sputter desorption. Instead, ethanol undergoes a surface dehydrogenation reaction on the metal-free silicon dioxide surface at $115 \mathrm{~K}$ to yield acetaldehyde before acquiring hydrogen from the surface during ion bombardment to desorb as $\mathrm{CH}_{3}-\mathrm{CH}=\mathrm{OH}^{+}$. As discussed before, the observation of both m/e 49 and m/e 50 peaks in Figure 2 suggests that the ethyl $\mathrm{C}-\mathrm{D}$ bond is disrupted when d-EtOD is exposed. The disruption occurring on the surface may induce a dehydrogenation reaction to yield acetaldehyde $\left(\mathrm{CD}_{3}-\mathrm{CD}=\mathrm{O}, \mathrm{m} / \mathrm{e} 48\right)$, whereas that occurring via surface ionization during sputter desorption does not lead to the formation of acetaldehyde on the sample surface.

TPD experiments were performed in which the desorption of the m/e 48 species was monitored to ensure the occurrence of ethanol conversion to acetaldehyde on the sample surface. The results are included in Figure 4. At d-EtOD exposure of $0.76 \mathrm{~L}$, the $m / e 48$ TPD spectrum exhibited a desorption feature peaking at the temperature of $225 \mathrm{~K}$, which was $14 \mathrm{~K}$ higher than the peak temperature of desorption measured at the same exposure for the m/e 52 (d-EtOD) species. Thus, the rise of the m/e 48 peak cannot be attributed to the fragmentation of deuterated ethanol in the TPD ionizer. In comparison to the standard electron-impact mass spectrum of ethanol, ${ }^{72}$ the observed larger peak intensity of desorption for $m / e$ than that for $m / e 52$, by about $10 \%$, also excluded the possibility that $m / e 48$ was mainly formed in the ionizer because of the fragmentation of m/e 52 .

The m/e 48 TPD spectrum taken from the sample surface exposed to $9.5 \mathrm{~L}$ deuterated ethanol showed a desorption peak located at a considerably lower temperature (191 K) than the one obtained at the exposure of $0.76 \mathrm{~L}$. This desorption temperature, however, coincided with the one observed in the m/e 52 TPD spectrum taken at the same ethanol exposure. As displayed in Figure 4, careful examination of the desorption behavior of m/e 52 showed that its peak temperature of desorption shifted to the lower temperature with the exposure. Furthermore, the peak intensity of desorption measured for $m / e$ 48 at $9.5 \mathrm{~L}$ exposure was lower than that for $m / e$ 52, and these two peaks showed similar desorption profiles on the lowtemperature side of the peak. The desorption feature observed at $191 \mathrm{~K}$ in the m/e $48 \mathrm{TPD}$ spectrum obtained at $9.5 \mathrm{~L}$ exposure was thus assigned as due to the fragmentation of $m / e 52$ in the TPD ionizer.

In addition to the desorption peak observed at $191 \mathrm{~K}$, the m/e 48 TPD spectrum taken at $9.5 \mathrm{~L}$ exposure also showed a shoulder on the high-temperature side of the peak. The temperature $(225 \mathrm{~K})$ at which the shoulder appeared was the same as the peak temperature of desorption observed in the m/e 48 TPD spectrum obtained at $0.76 \mathrm{~L}$ exposure. The observation of desorption signals at the same temperature in the m/e 48 TPD spectra taken from different exposures indicates that identical species may desorb from the surface at these exposures. The fact that a higher relative intensity of desorption was observed at the lower exposure of $0.76 \mathrm{~L}$ for $m / e 48$ than for $m / e 52$ reveals that the bare surface may facilitate the formation of $\mathrm{m} / \mathrm{e}$ 48 species, that is, $m / e 48$ is a product from the surface reaction of ethanol on silicon dioxide. As shown in Figure 4, the conversion of ethanol to m/e 48 subsides at high exposures when the surface active sites are occupied or consumed. Coupled with the SSIMS spectral analysis discussed above, the m/e 48 TPD signal appearing at $225 \mathrm{~K}$ is assigned as due to the desorption of acetaldehyde from the silicon dioxide surface. The SSIMS peak observed at $m / e 45$ in Figure 1 may thus originate from acetaldehyde on the surface acquiring hydrogen during sputter desorption. The presence of acetaldehyde on the surface before sputter desorption is consistent with the conclusion made earlier that $\mathrm{CH}_{3}-\mathrm{CH}=\mathrm{OH}^{+}$is the major species of the three possible forms of $\mathrm{EtO}^{+}$detected at m/e 45 .

Early studies ${ }^{46,83}$ have shown that in the presence of silica samples preheated to above $820 \mathrm{~K}$, ethanol can be dehydrogenated at reaction temperatures of above $570 \mathrm{~K}$ to yield acetaldehyde and hydrogen. A series of experiments carried out by Matsumura et al. ${ }^{68}$ in a pulse microcatalytic reactor showed that over the silica sample preheated at $1170 \mathrm{~K}$ in a vacuum for $30 \mathrm{~min}$, as high as $100 \%$ selectivity may be achieved for the conversion of ethanol to acetaldehyde when the reaction temperature was lower than $570 \mathrm{~K}$, although the corresponding conversion rate was as low as $4 \% .{ }^{68}$ The conversion rate dropped to $0 \%$ at the reaction temperature of $520 \mathrm{~K}$. It maximized at $670 \mathrm{~K}$ at an expense of the selectivity, that is, ethylene and carbon residues were also produced. This study, however, showed that acetaldehyde can be formed at the reaction temperature of as low as $115 \mathrm{~K}$ on the metal-free silicon dioxide sample prepared via thermal oxidation of silicon wafer and 
preheated to $950 \mathrm{~K}$ in a vacuum. The difference in the experimental results obtained may be partly due to the poor sensitivity of gas chromatography used in the analysis of reaction products in Matsumura's experiments. ${ }^{68}$ The suppression in the acetaldehyde yield observed in this study at high ethanol exposures can be ascribed to the coverage of the sample surface at $115 \mathrm{~K}$ by ethanol fragments and products.

3.5. Formation of Ethylene. As discussed above, the surface concentration of SiD increased quickly as the exposure of d-EtOD was increased. It may account for more than $50 \%$ of the signal intensity measured at $m / e$ 30. The higher surface concentrations of $\mathrm{D}$ atoms at increasing d-EtOD exposures should suppress the rate of $\mathrm{H} / \mathrm{D}$ exchange and result in a decrease in the yield of m/e $32\left(\mathrm{C}_{2} \mathrm{D}_{3} \mathrm{H}_{2}{ }^{+}\right)$species generated from deuterated ethyl $\left(\mathrm{C}_{2} \mathrm{D}_{5}{ }^{+}\right)$. Figure 2, however, shows that the ratio, $A_{32} / A_{34}$, of the SSIMS peak area measured at $m / e 32$ $\left(A_{32}\right)$ to that at m/e $34\left(A_{34}\right)$ does not vary substantially with the exposure, especially after initial exposures of ethanol. The ratio changes from 0.21 at $0.12 \mathrm{~L}$ exposure to 0.15 at $0.41 \mathrm{~L}$, to 0.13 at $0.76 \mathrm{~L}$, and to 0.10 at $3.5 \mathrm{~L}$. In comparison to $A_{33} /$ $A_{34}$, the magnitude of the $A_{32} / A_{34}$ ratio also does not agree with the kinetics of $\mathrm{H} / \mathrm{D}$ exchange, which predicts a significantly smaller rate for consecutive exchanges (i.e., for $m / e ~ 34$ to generate $m / e$ 32) than for single exchange (i.e., for $m / e ~ 34$ to generate $m / e$ 33).

The observed variation of $A_{32} / A_{34}$ with the exposure and the magnitude of $A_{32}$ thus indicates that in addition to the contribution from the H/D exchange of deuterated ethyl, the peak intensity obtained at $m / e 32$ in Figure 2 has to be attributed to other processes taking place on the sample surface. One of the possible processes is associated with the sputtering of ethylene $\left(\mathrm{CD}_{2}=\mathrm{CD}_{2}{ }^{+}\right)$. As reported in the literature, ethylene may be formed on the silica surface from dehydration of ethanol. ${ }^{39,67,68}$ The sputtering of ethylene should also contribute to the SSIMS intensity measured at $m / e 28$, at which $\mathrm{Si}^{+}$ions contribute, when normal ethanol is exposed to the sample (Figure 1).

The relative selectivity of the sample surface for ethanol conversion to produce ethylene and acetaldehyde at low substrate temperature of $115 \mathrm{~K}$ can be roughly estimated. As discussed before, the contribution of $\mathrm{d}-\mathrm{EtO}^{+}$ions to the $m / e 50$ peak intensity shown in Figure 2 is minimal. Instead, the $m / e$ 50 peak originates mainly from the sputtering of $\mathrm{CD}_{3}-\mathrm{CD}=$ $\mathrm{OD}^{+}$ions. The sum of the peak areas measured at $m / e 49$ $\left(\mathrm{CD}_{3}-\mathrm{CD}=\mathrm{OH}^{+}\right)$and $m / e 50$ may thus represent, to some extent, the quantity of acetaldehyde produced on the surface. In addition, the peak area obtained at $m / e 32$ (Figure 2) may reflect the production of ethylene on the surface because of the expected low yield from consecutive H/D exchanges. The dependence on the exposure of ethanol conversion to ethylene and acetaldehyde over silicon dioxide can then be investigated by assuming that the ionization probabilities of ethylene and acetaldehyde under ion bombardment for SSIMS detection are similar, since the ionization energy for acetaldehyde is 10.22 $\mathrm{eV}^{84,85}$ and that for ethylene is $10.51 \mathrm{eV} .{ }^{86,87}$ As shown in Figure $6 \mathrm{~A}$, the sputter yields, relative to the $\mathrm{Si}^{+}$( $m / e$ 28) yield, of both ethylene $(m / e ~ 32)$ and acetaldehyde $(m / e 49$ and m/e 50) increase rapidly with the ethanol exposure. Although the $\mathrm{Si}^{+}$yield is expected to decrease with the exposure in the high-exposure regime because of the surface coverage, which may cause the relative yields to increase somewhat, the observed rapid increase indicates that the silicon dioxide surface is reactive for ethanol conversion in the exposure range studied. Both dehydrogenation

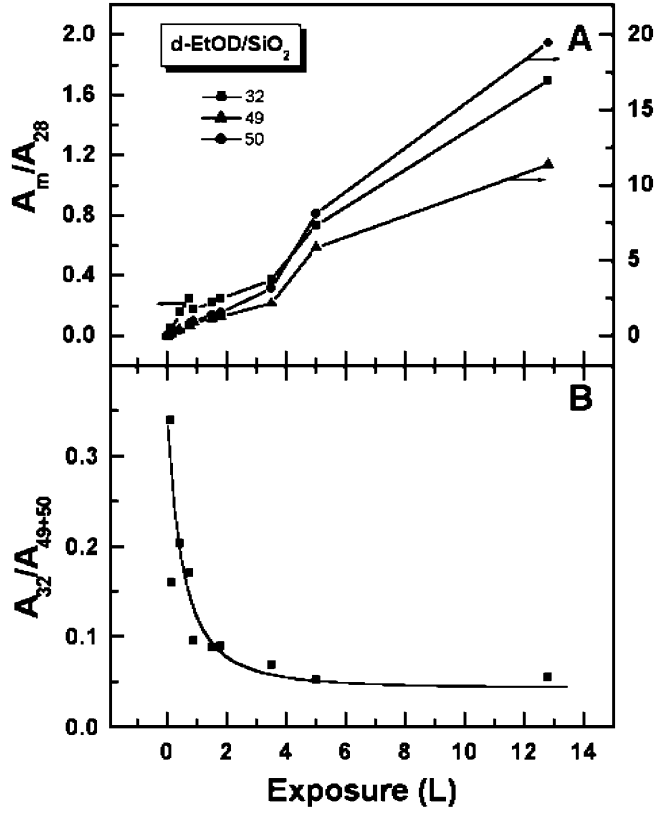

Figure 6. (A) Ratios of peak areas obtained at $\mathrm{m} / \mathrm{e}$ 32, 49, and 50 to the area of the m/e 28 peak in the SSIMS spectra of a silicon dioxide surface exposed to d-EtOD. (B) Ratio of the area of the m/e 32 peak to the sum of the peak areas obtained at $m / e 49$ and 50 in the SSIMS spectra of a silicon dioxide surface exposed to d-EtOD. All measurements were taken at $115 \mathrm{~K}$.

to produce acetaldehyde and dehydration to yield ethylene can thus take place on the surface at the low substrate temperature of $115 \mathrm{~K}$.

The selectivity of the sample surface for these two reactions, however, does not remain constant in the exposure range studied. Figure 6B shows the ratio of the SSIMS peak area for ethylene to that for acetaldehyde as a function of ethanol exposure. As the exposure is increased, the ratio decreases rapidly from 0.35 at $0.12 \mathrm{~L}$ exposure to 0.1 at $\sim 1.5 \mathrm{~L}$ exposure. Further increase in exposure does not cause the ratio to change drastically. The figure shows that, for ethanol reactions on silicon dioxide at $115 \mathrm{~K}$, more ethylene is produced on the bare surface than that at high exposures, although the production of acetaldehyde is favored over that of ethylene in the entire range of exposure studied. The selectivity toward dehydrogenation of ethanol in the presence of silicon dioxide increases with the exposure, with the ethylene yield amounting to $\sim 5 \%$ of the acetaldehyde yield at high exposures.

Other studies performed on dehydrated silica also observed the production of ethylene from ethanol. Thermogravimetrymass spectroscopy studies ${ }^{67}$ of silica calcined at more than 500 ${ }^{\circ} \mathrm{C}$ before being exposed to ethanol showed the formation of ethylene at $550{ }^{\circ} \mathrm{C}$ after ethanol was introduced. Analysis with gas chromatography of the products generated from ethanol exposure to a silica sample pretreated at $1170 \mathrm{~K}$ showed no production of ethylene until the reaction temperature was raised to above $620 \mathrm{~K} .{ }^{46,68}$ The selectivity for ethanol dehydration became greater, along with the total rate of conversion, at higher reaction temperatures. ${ }^{46,68}$ In contrast, this study showed that dehydration may take place on the bare silicon dioxide surface at low reaction temperature of $115 \mathrm{~K}$. Figures 1 and 2 show that its product, ethylene, however, accounts for a very small portion of the products yielded from ethanol reactions on silicon dioxide. The selectivity for ethylene formation also drops rapidly with the ethanol dose. Not until at high substrate temperatures would ethylene become the dominant product and was then 
detected by the analytical techniques employed in other studies. ${ }^{39,40,46,67,68}$

3.6. Surface Strain. The reactivity of the metal-free, pure silicon dioxide surface displayed in this study is very interesting. In addition to silanols, the strain present on the sample surface may aid in the dissociation of ethanol molecules. Extensive infrared studies ${ }^{55,61}$ have shown that when silica surfaces are dehydroxylated in a vacuum above $650{ }^{\circ} \mathrm{C}$, highly reactive surface sites are created. They are capable of chemisorbing molecules such as water, ${ }^{55}$ ammonia, ${ }^{55}$ methanol, ${ }^{88}$ and ethanol. ${ }^{46,68,89}$

The presence of surface strains on the sample surface was supported by the relatively large SSIMS intensity observed at m/e $44\left(\mathrm{SiO}^{+}\right)$in Figures 1 and 2. As mentioned above, the area of the $m / e 44$ peak obtained from the clean surface amounted to $\sim 19 \%$ of the one measured at $m / e 28$. This value was higher than the expected one for the desorbed $\mathrm{Si}$ and $\mathrm{O}$ atoms which were ejected from the silicon dioxide surface via certain correlated collision sequences. ${ }^{69,70}$ Thus, the formation of the $\mathrm{SiO}$ species during sputtering cannot be explained entirely by the recombination reactions above the surface. It is postulated that the strain developed in the siloxane bridges on the sample surface may facilitate sputtering of $\mathrm{SiO}$ from the sample. Quantum-chemical calculations of cluster models of silica surfaces showed that condensation of silanol groups led to the formation of strained siloxane bridges on the surface. ${ }^{90}$ Strains were developed in these bridges upon condensation because of the distortion of the bridge bond angles away from tetrahedral ${ }^{91}$ and to the restructuring of the silica matrix in the vicinity of these bridges. ${ }^{92,93}$ The silanol surface population of $2.6 \pm 0.5$ $\mathrm{OH} / \mathrm{nm}^{2}$ obtained above thus implied that the sample surface prepared in this study must contain strained siloxane bridges, which were produced via condensation of silanols during sample preparation and repeated annealing at $950 \mathrm{~K}$. The presence of strains and silanols on the sample surface, in turn, accounts for the large reactivity of the bare, metal-free silicon dioxide surface observed in this study toward ethanol decomposition.

\section{Concluding Remarks}

To provide a more detail understanding of the detrimental cause of surface reactions on the gate oxide of silicon MOS structures, studies on the model system of the adsorption and chemical reactions of ethanol on a metal-free, pure silicon dioxide sample have been performed. At the initial stage of exposure, EtOH molecules decomposed extensively on the sample surface via breakage of $\mathrm{C}-\mathrm{H}, \mathrm{Et}-\mathrm{OH}$, and $\mathrm{EtO}-\mathrm{H}$ bonds even at temperatures as low as $115 \mathrm{~K}$. The cleavage of the $\mathrm{C}-\mathrm{H}$ bond resulted in the production of acetaldehyde on the surface, which dominated the sputter desorption of $m / e 45$ under energetic ion bombardment. The disruption of the Et$\mathrm{OH}$ bond on the surface generated ethyl species, in which the $\mathrm{C}-\mathrm{H}$ bond may be further broken to yield ethylene. The selectivity of the silicon dioxide sample surface for ethanol conversion to acetaldehyde was higher than that to ethylene, although relatively more ethylene was yielded on the bare surface than on the one covered by ethanol fragments and products. The presence of silanols, with a surface density of $\sim 2.6 \mathrm{OH} / \mathrm{nm}^{2}$, on the sample surface prepared may promote the breakage and formation of the EtO- $\mathrm{H}$ bond, possibly with the aid of hydrogen bonding between surface silanol groups and hydroxyl groups in adsorbed molecules. Dehydrogenation of ethoxy, which was produced via disruption of the EtO-H bond, took place on the surface to form stable oxonium species. The high reactivity of the bare sample surface toward ethanol decomposition is accounted for by the presence of surface strains and silanols on the surface.

As observed by Atanassova et al., ${ }^{32}$ ethanol reactions with the silicon dioxide surface introduced defects in the siliconsilicon dioxide structure. The defects were a source of electrically active centers, which may lead to an increase in the charge density in the dielectric layer and at the interfaces under the drain voltage. ${ }^{10-12,32}$ Their studies ${ }^{32}$ showed that after the interaction of ethanol vapors with the silicon dioxide surface, the charge density increased from $<10^{9} \mathrm{~cm}^{-2}$ to $(1.5-1.7) \times$ $10^{11} \mathrm{~cm}^{-2}$. The surface charge on the oxide was mainly responsible for the ethanol-induced positive charge in the silicon-silicon dioxide structure. ${ }^{10,32}$ It was proposed that the surface charge was produced as a result of molecular polarization due to ethanol adsorption on the surface and of the generation and diffusion of the products formed from ethanol surface reactions. ${ }^{32}$ The observation of the weak dependence ${ }^{32}$ of the charge density on the level of surface saturation in ethanol vapor showed that the leakage current was limited mainly by the surface chemical reaction rather than the diffusion of the products and the possible chemical changes due to this diffusion.

This study showed that ethanol molecules and products could interact with siloxane and silanol bonds to various extents on the surface, which may contribute to the detrimental effects in the gate oxide. New $\mathrm{Si}-\mathrm{H}, \mathrm{SiO}-\mathrm{H}$, and $\mathrm{Si}-\mathrm{OEt}$ bonds were formed on the surface, in addition to the chemical bonds to the surface of acetaldehyde, ethylene, and other products created during ethanol surface reaction. Taking the formation of the $\mathrm{Si}-\mathrm{H}$ bond as an example, the discussions presented earlier showed that a substantial number of $\mathrm{Si}-\mathrm{H}$ bonds, accounted for $\sim 51 \%$ of the m/e 30 peak intensity observed in Figure 2, was generated when hydrogen atoms broke away from ethanol molecules during their reactions on the sample surface. The $\mathrm{Si}-\mathrm{H}$ bond is known to act like an electron donor. ${ }^{94}$ It weakens the neighboring siloxane bonds. The weak siloxane bond may be perturbed chemically ${ }^{16}$ by reaction or physically ${ }^{15,16}$ by ionizing radiation to produce trivalent silicon and nonbridging oxygen. ${ }^{20,21}$ Consequently, the surface reactivity and defect density are changed. In addition to the presence of hydrogen as $\mathrm{Si}-\mathrm{H}$ in silicon dioxide, ${ }^{95}$ it has been reported that hydrogen in the positive charge state may bind to an oxygen bridge of the silicon dioxide framework and form a 3-fold coordinated oxygen site. ${ }^{96}$ In the negative charge state, hydrogen bonds on a pentacoordinated silicon atom. ${ }^{96}$ It can also occupy the centers of the cages in silica in its neutral charge state and does not form bonds to the lattice. ${ }^{97}$

Hydrogen molecules in the background of the UHV analysis system may also be adsorbed and diffuse readily in silica. ${ }^{98,99}$ They occupy at least three different interstitial sites, which have the same deviation from centrosymmetry, of the silica network. ${ }^{100}$ At elevated temperatures, hydrogen molecules in these sites may dissociate to form hydrides $(\mathrm{SiH})$ and hydroxyl groups $(\mathrm{SiOH}) .{ }^{100}$ Once formed, these groups can be quenched to low temperatures without changing their relative concentrations or resulting in release of hydrogen. ${ }^{100}$ These hydrogen structures and those associated with different charge states of hydrogen atom in the sample may affect the electrical properties and the reactivity of the silicon dioxide surface. ${ }^{23,69}$

Similarly, new $\mathrm{SiO}-\mathrm{H}$ bonds formed from ethanol reactions on silicon dioxide provide a source of donorlike defects. ${ }^{16}$ These defects can be electrically activated by energetic electrons when the oxide is placed under the influence of the gate electric field. The energetic electrons injected to the $\equiv \mathrm{SiOH}$ centers will cause the cleavage of the $\mathrm{O}-\mathrm{H}$ bond, yielding oxygen dangling 
bonds. ${ }^{16,21}$ These nonbridging oxygen sites may undergo a second-order reaction ${ }^{16}$ with hydrogen molecules impregnated in the oxide to create more defects through the generation of hydrogen radicals. Such a reaction is feasible since its activation energy is as low as $1.07 \mathrm{eV},{ }^{16}$ considerably lower than the bond strength $(4.52 \mathrm{eV})^{101}$ of the diatomic molecular hydrogen because of the bond weakening due to valence electron screening by a factor roughly equivalent to the dielectric constant. The formation of $\mathrm{SiO}-\mathrm{H}^{16,61}$ and oxygen dangling bonds ${ }^{102}$ also enhances the reactivity of silicon oxide such that more electrically active defect centers will be produced.

The above-mentioned $\mathrm{H}$ - and $\mathrm{OH}$-induced structures as well as the ones induced by the formation of $\mathrm{Si}-\mathrm{OEt}$ bonds and by the presence of other ethanol products on the surface all give rise to defects when the gate oxide is exposed to ethanol vapor. Consequently, the electronic properties of the tetrahedral network of the dielectric layer are perturbed, which may result in the stress-induced leakage current when the silicon MOS structures exposed to chemical vapors are under biased voltage. ${ }^{32}$

Acknowledgment. We gratefully acknowledge financial support from the National Science Council of Taiwan, ROC. The authors also thank Pei-Hsuan Lee for his help on the preparation of the sample.

\section{References and Notes}

(1) Wolf, W. Modern VLSI Design; Prentice Hall: New Jersey, 2001.

(2) Hwang, H.-L. ULSI Technology Deep Submicron Device Processing \& Fabrication; Springer-Verlag: New York, 1998.

(3) Chang, C. Y.; Sze, S. M. ULSI Technology; McGraw-Hill: New York, 1996.

(4) Muller, D. A.; Sorsch, T.; Moccio, S.; Baumann, F. H.; EvansLutterodt, K.; Timp, G. Nature 1999, 399, 758. Schulz, M. Nature 1999 , $399,729$.

(5) Keyes, R. W. Proc. IEEE 1975, 63, 740.

(6) The International Technology Roadmap for Semiconductors, 2001, http://public.itrs.net/Files/2001ITRS/Home.htm.

(7) Risch, L. Mater. Sci. Eng. 2002, C19, 363.

(8) Wang, S. J.; Ong, C. K.; Xu, S. Y.; Chen, P.; Tjiu, W. C.; Huan, A.; Yoo, W. J.; Lim, J. S.; Feng, W.; Choi, W. K. Semicond. Sci. Technol. 2001, 16, L13.

(9) Conley, J. F., Jr.; Ono, Y.; Zhuang, W.; Tweet, D. J.; Gao, W.; Mohammed, S. K.; Solanki, R. Electrochem. Solid-State Lett. 2002, 5, C57.

(10) DiMaria, D. J.; Cartier, E.; Arnold, D. J. Appl. Phys. 1993, 73, 3367.

(11) Blochl, P. E.; Stathis, J. H. Physica 1999, B273, 1022.

(12) Blochl, P. E.; Stathis, J. H. Phys. Rev. Lett. 1999, 83, 372.

(13) DiMaria D. J. J. Appl. Phys. 1990, 68, 5234.

(14) Feigl, F. J.; Young, D. R.; Dimaria, D. J.; Lai, S.; Calise, J. J. Appl. Phys. 1981, 52, 5665.

(15) Kassabov, J.; Atanassova, E.; Dimitrov, D.; Goranova, E. SolidState Electron. 1988, 31, 147 and references therein. 944.

(16) Sah, C.-T.; Sun, J. Y.-C.; Tzou, J. J.-T. J. Appl. Phys. 1983, 54,

(17) Kassabov, J.; Atanassova, E.; Goranova, E.; Dimitrov, D.; Vasileva, J. Solid-State Electron. 1989, 32, 535.

(18) Schwerin, A. V.; Heyns, M. M.; Weber, W. J. Appl. Phys. 1990 67, 7595 .

(19) Stathis, J. H.; Cartier, E. Phys. Rev. Lett. 1994, 72, 2745.

(20) Sah, C. T.; Sun, J.; Tzou, J. J. Appl. Phys. 1982, 53, 8886.

(21) Rosencher, E.; Bois, D. Appl. Phys. Lett. 1982, 40, 601.

(22) Griscom, D. L. J. Electron. Mater. 1992, 21, 762.

(23) DiMaria, D. J.; Cartier, E. J. Appl. Phys. 1995, 78, 3883.

(24) Revesz, A. G. J. Electrochem. Soc. 1979, 126, 122

(25) McFeely, F. R.; Cartier, E.; Terminello, L. J.; Santoni, A.; Fischetti, M. V. Phys. Rev. Lett. 1990, 65, 1937.

(26) Fischetti, M. V.; Dimaria, D. J.; Brorson, S. D.; Theis, T. N.; Kirtley, J. R. Phys. Rev. 1985, B31, 8124.

(27) Buchanan, D. A.; Fischetti, M. V.; DiMaria, D. J. Phys. Rev. 1991, B43, 1471 .

(28) Heyns, M. M.; Schwerin, A. V. Insulating Films on Semiconductors Eccleston, W., Uren, M., Eds.; Adam Hilger: New York, 1991; p 73-82.

(29) Stahlbush, R. E.; Cartier, E.; Buchanan, D. A. Microelectron. Eng. $1995,28,15$.

(30) Cartier, E.; Stathis, J. H. Microelectron. Eng. 1995, 28, 3.
(31) Nicollian, E. H.; Berglund, C. N.; Schmidt, P. F.; Andrews, J. M. J. Appl. Phys. 1971, 42, 5654.

(32) Atanassova, E.; Dimitrova, T. Solid-State Electron. 1993, 36, 1711.

(33) Giorgi, J. B.; Schroeder, T.; Baumer, M.; Freund, H.-J. Surf. Sci. 2002, 498, L71.

(34) Schroeder, T.; Hammoudeh, A.; Pykavy, M.; Magg, N.; Adelt, M.; Baumer, M.; Freund, H.-J. Solid-State Electron. 2001, 45, 1471.

(35) Bond, G. C. Handbook of Heterogeneous Catalysis; Ertl, G., Knozinger, H., Weitkamp, J., Eds.; VCH Verlagsgesellschaft mbH: Weinheim, Germany, 1997; pp 752-770.

(36) Parmaliana, A.; Sokolovskii, V.; Micelli, D.; Arena, F.; Giordiano, N. J. Catal. 1994, 148, 514.

(37) Schoderbock, P.; Lahaye, J. Appl. Surf. Sci. 1996, 93, 109.

(38) Zhang, W.; Desikan, A.; Oyama, S. T. J. Phys. Chem. 1995, 99, 14468.

(39) Crowell, J. E.; Tedder, L. L.; Cho, H.-C.; Cascarano, F. M.; Logan, M. A. J. Vac. Sci. Technol. 1990, A8, 1864.

(40) Tedder, L. L.; Lu, G.; Crowell, J. E. J. Appl. Phys. 1991, 69, 7037.

(41) Pereyra, I.; Alayo, M. I. J. Non-Cryst. Solids 1997, 212, 225

(42) Adams, A. C. Solid State Technol. 1983, 26, 135. Kim, S. S.; Tsu,

D. V.; Lucovsky, G. J. Vac. Sci. Technol. 1988, A6, 1740.

(43) He, Z.; Leung, K. T. Appl. Surf. Sci. 2001, 174, 225.

(44) Schroeder, T.; Adelt, M.; Richter, B.; Naschitzki, M.; Baumer, M.;

Freund, H.-J. Surf. Sci. Lett. 2000, 7, 7.

(45) Vix-Guterl, C.; Lahaya, J.; Ehrburger, P. Fuel 1997, 76, 517

(46) Matsumura, Y.; Hashimoto, K.; Yoshida, S. J. Chem. Soc. Chem. Commun. 1987, 1599 .

(47) Chang, C.-C.; Huang, I.-J.; Lung, C.-H.; Hwang, H.-Y.; Teng, L.-

Y. J. Phys. Chem. 2001, 105, 994.

(48) Ishizaka, A.; Shiraki, Y. J. Electrochem. Soc. 1985, 133, 666.

(49) Harrison, D. E., Jr.; Kelly, P. W.; Garrison, B. J.; Winograd, N. Surf. Sci. 1978, 76, 311.

(50) Chang, C.-C.; Winograd, N. Phys. Rev. 1989, 39, 3467.

(51) Chang, C.-C.; Hsieh, J.-Y. Phys. Rev. 1998, B57, 12564.

(52) Hayashi, Y.; Matsumoto, K. J. Ceram. Soc. Jpn. 1992, 100, 1038

(53) Wood, B. J.; Lamb, R. N.; Raston, C. L. Surf. Interface Anal. 1995 23,680

(54) Iler, R. K. The Chemistry of Silica; Wiley-Interscience: New York, 1979; Chapter 6.

(55) Morrow, B. A.; Cody, L. A. J. Phys. Chem. 1976, 80, 2761.

(56) Hoffmann, P.; Knozinger, H. Surf. Sci. 1987, 188, 181.

(57) O'Keeffe, M.; Gibbs, G. V. J. Chem. Phys. 1984, 81, 876.

(58) Lygin, V. I.; Serazetdinov, A. D.; Chertikhina, O. L. Zh. Fiz. Khim. 1989, 63, 2948.

(59) D’Souza, A. S.; Pantano, C. G.; Kallury, K. M. R. J. Vac. Sci. Technol. 1997, A15, 526.

(60) Zhuravlev, L. T. Colloids Surf. 1993, A74, 71.

(61) Morrow, B. A.; Cody, L. A. J. Phys. Chem. 1976, 80, 1995.

(62) Ballinger, T. H.; Yates, J. T., Jr. Langmuir 1991, 7, 3041.

(63) Knozinger, H. Surface Organometallic Chemistry: Molecular Approaches to Surface Catalysis; Basset, J.-M., Ed.; Kluwer Academic Publishers: New York, 1988; pp 35-46.

(64) Boehm, H.-P.; Knozinger, H. In Catalysis: Science and Technology; Anderson, J. R., Boudart, M., Eds.; Springer: Berlin, 1983; Vol. 4, pp 40189.

(65) Zaki, M. I.; Hasan, M. A.; Al-Sagheer, E. A.; Pasupulety, L. Colloids Surf. 2001, 190, 261.

(66) Fleish, T.; Ott, G. L.; Winograd, N.; Delgass, W. N. Surf. Sci. 1978 $78,141$.

(67) Ho, S.-W.; Su, Y.-S. J. Catal. 1997, 168, 51

(68) Matsumura, Y.; Hashimoto, K.; Yoshida, S. J. Catal. 1989, 117, 135.

(69) Winograd, N.; Harrison, D. E., Jr.; Garrison, B. J. Surf. Sci. 1978 78,467

(70) Chang, C.-C. Phys. Rev. 1993, B48, 12399

(71) Budzikiewicz, H.; Djerassi, C. D.; Williams, D. H. Interpretation of Mass Spectra of Organic Compounds; Holden-Day: San Francisco, CA, 1964.

(72) Silverstein, R. M.; Bassler, G. C.; Morrill, T. C. Spectrometric Identification of Organic Compounds, 5th ed.; Wiley: New York, 1991

(73) Saracual, A. R. A.; Pulton, S. K.; Vicary, G.; Rochester, C. J. Chem Soc., Faraday Trans. 1982, I78, 2285.

(74) Plueddermann, E. P. Silane Coupling Agents; Plenum Press: New York, 1982

(75) Curtiss, L. A.; Lucas, D. J.; Pople, J. A. J. Chem. Phys. 1995, 102, 3292.

(76) Little, L. H. Infrared Spectra of Adsorbed Species; Academic Press: New York, 1966

(77) Ramond, T. M.; Davico, G. E.; Schwartz, R. L.; Lineberger, W. C. J. Chem. Phys. 2000, 112, 1158 .

(78) Dang, T. T.; Motell, E. L.; Travers, M. J.; Clifford, E. P.; Ellison, G. B.; Depuy, C. H.; Bierbaum, V. M. Int. J. Mass Spectrom. Ion Processes 1993, $123,171$. 
(79) Ruscic, B.; Berkowitz, J. J. Chem. Phys. 1994, 101, 10936.

(80) Mizukami, M.; Kurihara, K. Chem. Lett. 2000, 256.

(81) Nobes, R. H.; Bouna, W. J.; Radom, L. J. Am. Chem. Soc. 1983, $105,309$.

(82) Egsgaard, H.; Carlsen, L. Chem. Phys. Lett. 1995, 236, 78.

(83) Matsumura, Y.; Hashimoto, K.; Yoshida, S. J. Catal. 1990, 122, 352.

(84) Traeger, J. C. Int. J. Mass Spectrom. Ion Processes 1985, 66, 271

(85) Hernandez, R.; Masclet, P.; Mouvier, G. J. Electron Spectrosc. Relat. Phenom. 1977, 10, 333.

(86) Ohno, K.; Okamura, K.; Yamakado, H.; Hoshino, S.; Takami, T.; Yamauchi, M. J. Phys. Chem. 1995, 99, 14247.

(87) Williams, B. A.; Cool, T. A. J. Am. Chem. Soc. 1991, 94, 6358.

(88) McCormick, R. L.; Al-Sahali, M. B.; Alptekin, G. O. Appl. Catal. 2002, A226, 129.

(89) Matsumura, Y.; Hashimoto, K.; Yoshida, S. J. Mol. Catal. 1991, 68,73
(90) Lygin, V. I. Zh. Fiz. Khim. 1989, 63, 289

(91) Fink, M. J.; Haller, K. J.; West, R.; Michl, J. J. Am. Chem. Soc. 1984, 106, 822 .

(92) Morrow, B. A.; Devi, A. Trans. Faraday Soc. 1972, 68, 403.

(93) Bunker, B. C.; Haaland, D. M.; Ward, K. J.; Michalske, T. A.; Smith, W. L.; Binkley, J. S.; Melius, C. F.; Balfe, C. A. Surf. Sci. 1989, $210,406$.

(94) Sah, C.-T.; Sun, J. Y.-C.; Tzou, J. J. J. Appl. Phys. 1983, 54, 944

(95) Blochl, P. E.; Stathis, J. H. Physica 1999, B273, 1022.

(96) Yokozawa, A.; Miyamoto, Y. Phys. Rev. 1998, B55, 13783.

(97) Weeks, R. A.; Abraham, M. J. Chem. Phys. 1965, 42, 68.

(98) Shelby, J. E. J. Non-Cryst. Solids 1994, 179, 138

(99) Ecans, B. D. IEEE Trans. Nucl. Sci. 1988, 35, 1215.

(100) Schmidt, B. C.; Holtz, F. M.; Beny, J.-M. J. Non-Cryst. Solids 1998, 240, 91 .

(101) Handbook of Chemistry and Physics, 83rd ed.; Lide, D. R., Ed.; CRC Press: Cleveland, OH, 2002.

(102) Konecny, R. J. Phys. Chem. 2001, 105, 6221. 